\title{
ENSINO E APRENDIZAGEM DE ANÁLISE MATEMÁTICA COMO ENCONTRO COM OS SIGNOS NA PERSPECTIVA DE GILLES DELEUZE
}

\author{
Luiz Carlos leal Junior \\ Instituto Federal de São Paulo (IFSP), Sertãozinho, São Paulo, Brasil \\ Antonio dos Santos Andrade \\ Universidade de São Paulo (USP), Ribeirão Preto, São Paulo, Brasil
}

\begin{abstract}
RESUMO: O presente artigo apresenta reflexões acerca da disciplina de Análise Matemática em cursos de ciências exatas de um ponto de vista filosófico. O principal objetivo é atentar para questões críticas do ensino e da aprendizagem desta disciplina. Para investigar este objeto de estudo como signo e um acontecimento no pensamento, busca-se uma análise sobre a problemática desta disciplina com base na teorização de Gilles Deleuze e seu deslocamento conceitual para o campo da Educação Matemática. Esse pensador propõe pensarmos o aprender como processo, como passagem, como acontecimento no pensamento. Com essa perspectiva o aprendizado da Análise Matemática passa a ser concebido como o desenvolvimento de uma sensibilidade dos aprendizes aos signos desta matéria e se torna a condição para a sua efetivação.
\end{abstract}

PALAVRAS-CHAVE: Análise Matemática. Signos. Ensino e Aprendizagem. Gilles Deleuze.

INTRODUÇÃO

A Análise Matemática, bem como a Geometria e a Matemática Aplicada, formam um espectro fundamental para a Matemática escolar e acadêmica da atualidade em nosso país. Em muitos países de idioma castelhano 
ou inglês, fala-se em as "Matemáticas", em vez de a "Matemática", como pode ser percebido em Pascual (2009) e Pickover (2014). Aqui nos restringiremos a tratar apenas da Matemática que é feita através da Análise Matemática, que vem a ser uma base e uma fonte geradora para as Matemáticas que são apresentadas no meio educacional, e que muitas vezes se confundem e mesclam-se, em princípio, com a própria Matemática. Não estamos propondo uma Análise metonímica, ou seja, tomar a parte da Análise Matemática pelo todo da Matemática, ou dizer que os problemas que a permeiam são os mesmos de outras áreas. Mas estamos propondo que a própria Análise Matemática perpassa transversalmente todas as ciências Matemáticas, e que seus elementos estruturantes são comuns às mesmas, conforme propomos.

Mas, afinal, o que é a Análise Matemática? Quais são os princípios e as implicações na Matemática que conhecemos?

A seguir, apresentamos alguns autores que tratam dessa Matemática, a definem e a explicitam em pesquisas e trabalhos de cunho matemático, educacional e aplicado. Essa visão, a qual se faz presente na estruturação da disciplina de Análise Matemática em nossos cursos de graduação, tem forte influência da Matemática cartesiana, que podemos perceber através dos recortes abaixo citados.

Para Sotomayor (2004, p. 2), “a Análise Matemática é tão extensa como a própria Natureza; ela define todas as relações perceptíveis, mede os tempos, espaços, forças e temperaturas. Esta ciência difícil evolui lentamente, mas preserva cada princípio uma vez adquirido, assimilando-o; cresce e se fortalece incessantemente apesar da variabilidade e dos erros da mente humana". O autor também a relaciona a uma linguagem que nos possibilita interpretar os fenômenos da Natureza de uma forma que "a Análise Matemática pode ainda exprimir as leis que descrevem estes fenômenos. Os tornam presentes e mensuráveis, como se fosse um atributo da mente humana destinada a completar a brevidade da vida e a imperfeição dos sentidos" (SOTOMAYOR, 2004, p. 2).

Silva (2009) e Roque (2012) propõem que a Análise Matemática se constituiu como uma ciência dentro da Matemática com o intuito de fundamentá-la, seja no âmbito do Cálculo infinitesimal ou da Análise algebrizada. Essa perspectiva vem desde Bernoulli e Euller, no século XVIII, aos nossos dias atuais. Os autores nos trazem uma percepção histórica da mesma enquanto uma Matemática ou uma ciência e, ainda, como se constituiu em uma componente curricular e um meio de produção de sentido e significado à Matemática escolar e acadêmica (doravante apenas Matemática), sobre a qual não nos deteremos neste trabalho. 
Estas citações apontam para a Análise Matemática (doravante apenas Análise - iniciada com letra maiúscula) como a fundamentação das nossas Matemáticas e, por conseguinte, assestam para sua essência e constituição, sobre as quais trabalharemos com a teorização do filósofo francês Gilles Deleuze.

Ao olhar para a Análise, na qualidade de uma região de inquérito, um componente curricular, percebemos que desde 1821, após o Cours d'Analyse de l'École Royale Polytechnique, ministrado pelo matemático Augustin-Louis Cauchy, ela é ensinada com constância e regularidade, direta ou indiretamente como disciplina, nos cursos de bacharelado, licenciatura e superiores de tecnologia na área de ciências exatas.

Contudo, a Análise figura no cenário da Educação Superior com uma nomenclatura variada, como, por exemplo: Análise Matemática I e Análise Matemática II, Análise A e Análise B, Análise Real, Análise na Reta, Espaço de Funções, Introdução à Análise, entre outros nomes. Em suma, trata-se de uma componente curricular que aborda, em suas ementas e planos de curso, assuntos (numa forma ampla de concepção de curso) como: Conjuntos, Funções, Números reais, Sequências e séries de números reais, Topologia da reta, Limites de funções, Funções contínuas, Derivação, Integral de Riemann, Sequências e séries de funções, Espaços vetoriais normados, Topologia do espaço, Convergência e continuidade, Homeomorfismos, Continuidade uniforme, Extensão contínua e limites, Funções diferenciáveis, Funções de classe $\mathrm{Cq}$, Derivada de funções compostas, Desigualdade do valor médio, Funções implícitas.

$\mathrm{Na}$ esteira dessas considerações, a Análise é um meio repleto de simbolismos e de uma gramática próprios, que, considerando os modos e a problemática que ecoam de suas propostas de ensino e de aprendizagem, reafirmam e intensificam o status quo da processualidade que a cerca, como veremos a seguir. Todavia, acreditamos que nela e por meio dela os signos da Matemática são constituídos e percebidos.

\section{A situação crítica da Análise Matemática}

Há no meio acadêmico muitos textos que retratam problemas referentes ao ensino e à aprendizagem da Análise e do Cálculo diferencial e integral, como Cury (2005), Nascimento (2000), Silva (2011), Nasser, Freire e Cardador (2008), Otero-Garcia (2011) e Otero-Garcia e Cammarota (2012). 
Alguns deles apresentam questões relacionadas a partir de levantamentos bastante significativos nos últimos dez anos na base de dados da CAPES e em Anais de eventos nacionais sobre Educação Matemática.

Nesses trabalhos, pudemos nos deparar com narrativas e entrevistas com docentes da disciplina de Análise Matemática, em que os autores a retratam de forma bastante diferenciada. Nos trabalhos de Otero-Garcia (2011) e de Otero-Garcia e Cammarota (2012), por exemplo, uma das problemáticas em torno da Análise está na formação e no domínio de seu conteúdo por parte dos docentes. E consideram que estes, por sua vez, deveriam conceder autonomia crescente aos aprendizes, para que construam as próprias resoluções, desenvolvam as colaborações, fomentem as discussões em torno das diversificadas maneiras de pensar um determinado problema e sustentem as resoluções, incentivando o questionamento e o senso crítico.

Otero-Garcia (2011) e Otero-Garcia e Cammarota (2012) apontam ainda que, para egressos de cursos que possuem Análise em sua estrutura, não há relação entre essa disciplina e seu campo de atuação profissional e, portanto, ela deveria ser extinta do currículo. Também foram estudados os impactos que marcam a transição do cálculo para a Análise; a questão dos pré-requisitos e as dificuldades dos estudantes com relação à disciplina de Análise; a necessidade e a essencialidade da Análise a determinadas formações, em destaque a do professor de Matemática; o modo irregular e desconexo com que esta disciplina se configura no currículo; e as razões de tal inserção, que são postas de maneira obscura e desordenada.

Para Nascimento (2000), grande parte das dificuldades dos alunos nos cursos de Análise provém de déficit de aprendizagem nas disciplinas que Ihe servem de pré-requisito. Essa problemática reside no fato de os docentes do ensino superior não possuírem, em sua maioria, um preparo adequado ao exercício de sua função.

Otero-Garcia (2011) expõe que a Análise não-standard vem para solucionar e (res)significar os problemas existentes com o conceito de infinitesimais, os quais são inerentes a essa região de inquérito. Ele ressalta que na física há essa separação de ideias da Matemática, de modo a conferir ao estudante uma melhor compreensão do assunto e maiores aplicabilidade e visualização dos conceitos.

Segundo Nascimento (2000), as principais deficiências apresentadas por alunos em Cálculo, e também em Análise, constituem-se de problemas elementares de manipulação algébrica, num nível tão elementar que, por via de regra, são estudados ainda no ensino fundamental. 
No que se refere ao grande número de evasões em cursos de graduação, esses autores salientam que é devido à falta de versatilidade dos currículos escolares perante às constantes mudanças e transformações no mundo do trabalho e, consequentemente, resultam em uma crescente desatualização dos cursos e no desinteresse, por parte dos estudantes que não conseguem interpretar o que lhes é ensinado/repassado - o que retrata, de maneira plena, a situação crítica desta disciplina na atualidade.

Dentre as questões que consideramos críticas sobre a temática em questão, nos atentaremos às que seguem: Por que o aprender a pensar Análise é tão difícil para a maioria dos estudantes? Quais as ressonâncias entre o aprender e o ensinar Análise?

Não fornecemos, aqui, repostas diretas a estas perguntas, mas possibilitamos uma discussão sobre a problemática e expomos nossa compreensão sobre o tema.

Apresentamos a seguir, as falas dos participantes da disciplina "Discussão Crítica de Artigos em Educação Matemática", oferecida no segundo semestre de 2013, no Programa de Pós-Graduação em Educação Científica e Tecnológica - PPGECT da Universidade Federal de Santa Catarina - UFSC, quando de uma conversa sobre a importância e a influência da Análise na formação de professores de Matemática. Essa interlocução emergiu da apresentação de um seminário, em que os apresentadores trouxeram essa problemática para discussão, e buscaram compreender o que os professores de Matemática pensam sobre tal componente curricular. Essas falas vêm ratificar as pesquisas dos autores supracitados, quais sejam, Nascimento (2000) e Otero-Garcia (2011). Aqui omitiremos os nomes dos participantes para preservar a identidade dos mesmos.

- Um primeiro pensar que tive sobre a disciplina de Análise na graduação foi que ela seria fora do meu intuitivo, do meu mundo padronizado do cálculo. Creio que as dificuldades estejam muito mais ligadas do que cremos ter a capacidade de aprender, não por competência e incompetência, mas algo ligado à nossa racionalidade (do padrão do que consideramos ser capazes).

- É difícil pensar a disciplina, pois desde o início do curso de licenciatura escutamos que essa disciplina é a mais difícil e a mais importante para entrar no mestrado, por exemplo, e, para isso, ela deve ser cursada no bacharelado. Dependerá do professor a dificuldade da mesma.

- A disciplina está bastante distante dos conteúdos matemáticos que ensinaremos na escola e, dessa forma, os alunos de licenciatura não enxergam um objetivo nessa disciplina, pois ela parece ser descontextualizada. 
- Pensar Análise é difícil quando não se tem continuidade com o cálculo, e é ainda mais difícil quando esta última é falha. Ela parece um conjunto isolado de informações.

— O pensamento acerca da Análise talvez esteja ligado na recognição em que se está preso a um modelo; as linhas de fuga estão obscuras, opacas. Pensar, ensinar nesta lógica afasta-se do proposto por uma perspectiva deleuzeana de um pensar vital, alegre e energético.

- Na medida em que ela se apresenta como Matemática pura, busca "acomodar" os alunos, buscando homogeneizá-los, pois ela os uniformiza. - Análise ocupa um lugar histórico no curso. É uma disciplina final que divide espaço com estágios, trabalho de conclusão de curso (no máximo, Métodos Numéricos), além de suceder os cálculos. Ela parece à parte, ritual de um processo formativo. Sua aprovação é a coroação de um mortal em Matemática. Parece que tem um grande peso e endereça aos alunos um prazer intelectual. Acho que o questionamento prejudica ou ajuda, não cabe. A questão é como ela subjetiva os sujeitos. (Material dos autores, 20/11/2013).

De partida, temos que destacar os conceitos a que iremos recorrer em nossas considerações posteriores. Dessa forma, faz-se necessário introduzir, aqui, uma concepção de Aprendizagem que nos possibilite compreender as origens destas dificuldades.

\section{OS SIGNOS, O ENSINO E A APRENDIZAGEM}

A noção de Signo permeia boa parte das obras de Gilles Deleuze. Em Proust e os signos (2003), o autor se dedica a nos mostrar que o aprendizado está diretamente ligado à natureza dos Signos. Para Deleuze, todo ato de aprender está relacionado à interpretação dos signos ou ao relacionamento com eles.

Aprender diz respeito essencialmente aos signos. Os signos são objeto de um aprendizado temporal [...], não de um saber abstrato. Aprender é, de início, considerar uma matéria, um objeto, um ser, como se emitissem signos a serem decifrados, interpretados. Não existe aprendiz que não seja "egiptólogo" de alguma coisa. Alguém só se torna marceneiro tornando-se sensível aos signos da madeira, e médico tornando-se sensível aos signos da doença. $A$ vocação é sempre uma predestinação com relação a signos. Tudo que nos ensina alguma coisa emite signos, todo ato de aprender é uma interpretação de signos ou de hieróglifos (DELEUZE, 2003, p. 4). 
Em Diferença e Repetição, Deleuze (1998, p. 237), apresenta uma concepção de Aprendizagem, segundo a qual aprender é conjugar "pontos notáveis" do corpo (ou da mente) de quem aprende com os "pontos singulares da Ideia objetiva" (os signos). Esta conjunção se constitui como um "campo problemático" (DELEUZE, 1998, p. 237). É ao mesmo tempo em que a conjunção se faz que ela se constitui como campo problemático, ou seja, problema, não existindo condições para que um processo de aprendizagem se inicie. O resultado da aprendizagem será a produção de soluções para o problema colocado. Daí, Deleuze (1998, p. 236) diz que:"aprender é o nome que convém aos atos subjetivos operados em face da objetividade do problema (ideia)" e a ele se pode contrapor o"saber" ou a"recognição": "ao passo que saber designa apenas a generalidade do conceito ou a calma posse de uma regra de soluções".

Do lado do aprendiz, esta conjunção estabelece "um limiar de consciência" ao nível do qual os seus atos reais se ajustam às suas percepções das correlações objetivas do problema. Do outro lado, os pontos singulares da Ideia objetiva são elementos a priori da Natureza e objeto subliminar de pequenas percepções. Sendo assim, "'aprender' passa sempre pelo inconsciente, passa-se sempre no inconsciente, estabelecendo, entre a natureza e o espírito, o liame de uma cumplicidade profunda" (DELEUZE, 1998, p. 237). Neste aspecto, aprender consiste sempre em "penetrar no universal das relações que constituem a Ideia e nas singularidades que lhes correspondem" (DELEUZE, 1998, p. 237). É por isto que Deleuze (1998, p. 237) pode afirmar:"nunca se sabe de antemão como alguém vai aprender - que amores o tornam bom em latim, com quais encontros se é filósofo, em que dicionários se aprende a pensar".

A aprendizagem é sempre um acontecimento singular, criativo, inventivo, inovador, nunca repetido, pois os pontos notáveis do aprendiz, que são sempre singularidades pré-individuais, não acessíveis à consciência, se conjugam a pontos singulares, também pré-individuais, daquilo com o que ele está em relação de aprendizagem, a Ideia objetiva, o que resulta numa composição que só pode ser, por sua vez, completamente singular, inventiva e inconsciente.

A aprendizagem não se referirá aqui ao ensino, mas se dará no encontro com os signos. Ela é a constituição de um modo de existir que se dá na afetação pelos signos emitidos pela matéria. Não é de um sujeito em relação a um objeto ou ideia, mas refere-se à produção de um corpo. Não se restringe à ordem de um sujeito que ensina conteúdos a um sujeito que deve aprendê-lo (DELEUZE, 2003). 
Em oposição à Aprendizagem, Deleuze e Guattari (1995) afirmam que os professores, ao fazerem uso da linguagem, exercem poder e autoridade sobre os alunos, uma vez que, ao "ensignarem", apenas dão ordens e comandam.

Os mandamentos do professor não são exteriores nem se acrescentam ao que ele nos ensina. [...] A linguagem não é feita para que se acredite nela, mas para obedecer e fazer obedecer. [...] A linguagem não é a vida, ela dá ordem à vida, a vida não fala, ela escuta e aguarda (DELEUZE; GUATARRI, 1995, p. 11).

Desta forma teríamos uma "ensignagem" que, ao conceber o ensino apenas como transmissão de regras e normas, como numa linguagem, se opõe à Aprendizagem, que implica sempre num encontro com os signos da matéria objetivada, que só pode ser realizada pela experiência, pela afecção, pelo contato, conexão, conjunção. Na Aprendizagem, o contato tem que ser imediato entre os pontos notáveis do aprendiz e os aspectos singulares da ideia objetiva (os signos), que acontecem sempre de uma forma singular e até mesmo involuntária ou inconsciente. Caberia ao professor favorecer a oportunidade para que os alunos se encontrem com signos, sejam afetados por signos, decifrem os signos, apresentando-lhes a matéria a partir da qual estes signos possam ser atualizados, nesses "encontros".

No entanto, há em trabalhos divulgados em meios acadêmicos, como em Sotomayor (2004) e em Corrêa (2005), a noção de Matemática como "um meio de comunicação - dotado de um código, uma linguagem e uma gramática próprios - utilizados por uma comunidade".

Embora haja, no ensino médio, conteúdos (como conjuntos numéricose funções) que são base para se pensar, mesmo que de forma embrionária e como algo inaugural no pensamento, alguns conceitos pertinentes à Análise, eles são apresentados aos estudantes sem ao menos possibilitar-lhes que antevejam seus porquês, haja vista a forma representativa, tradicional e enciclopédica que rege o nosso sistema educacional. Temos aí um momento em que os estudantes poderiam sensibilizar-se com signos fundamentais para o encontro posterior com a Análise, mas a preocupação de apenas "ensinar" normas, regras, como numa linguagem, forçando à recognição, em lugar de uma Aprendizagem de fato, pode estar impedindo a construção dos seus alicerces fundamentais.

O que evidenciamos no cenário escolar é o ensino de Matemática como saber ou recognição, em lugar do aprender. Aí reside o problema do ensino e da aprendizagem de Matemática. Se concebermos a Análise Matemática como algo mais empírico que linguístico, talvez possamos compreender a 
grande dificuldade de sua aprendizagem. Pois, se tratada como se fosse uma linguagem, cujos códigos e sintaxes têm que ser dominados, talvez estejamos excluindo a possibilidade de um "encontro" do aprendiz com o que constitui, de fato, a Análise, os seus signos.

"Pensar é deixar ser violentado pelo signo que rouba a nossa paz, que violenta o pensamento" (PETRONILIO, 2012, p. 51), como algo (exterior) que nos força a alguma coisa, que é exterior à nossa vontade. Signos esses que são entes ontológicos e não têm relações idiossincráticas com a linguagem.

Aqui propomos a Matemática enquanto área que busca decifrar signos da realidade, tais como: quantitabilidade, qualitabilidade e potencialidade, nos termos de Deleuze (1998). Portanto, a Matemática não é apenas uma linguagem, é uma área do conhecimento sobre a Natureza que busca decifrar signos, o que aponta para seu matiz ontológico.

A partir de Deleuze (1998), entendemos a indicação da quantitabilidade, da qualitabilidade e da potencialidade como classes de signos da Matemática. Assim, para o autor, a quantitabilidade seria:

A ldeia de fogo subsume o fogo como uma só massa contínua, suscetível de crescimento. A Ideia de dinheiro subsume seu objeto como uma continuidade líquida de metal fino. Mas se é verdade que o contínuo deve ser referido à Ideia e a seu uso problemático, é com a condição de não ser definido por características tomadas da intuição sensível ou mesmo geométrica, como acontece ainda quando se fala de interpolação de intermediários, de sequências intercalares infinitas ou de partes que nunca são as menores possíveis. O contínuo só pertence verdadeiramente à Ideia na medida em que se determina uma causa ideal da continuidade. A continuidade, tomada como sua causa, forma o elemento puro da quantitabilidade. Este não se confunde com as quantidades fixas da intuição (quantum), nem com as quantidades variáveis como conceitos do entendimento (quantitas). Portanto, o símbolo que o exprime é inteiramente indeterminado: $\mathrm{dx}$ nada é em relação a $x$, como dy em relação a y. Mas todo problema está na significação destes zeros. Como objetos da intuição, os quantas têm sempre valores particulares; e mesmo unidos numa relação fracionária, cada um guarda um valor independente de sua relação. [...] Compete às Matemáticas modernas precisar a natureza deste universal do número como consistindo no "corte" (no sentido de Dedekind): é o corte, neste sentido, que constitui o gênero próximo do número, a causa ideal da continuidade ou o elemento puro da quantitabilidade (DELEUZE, p. 165-166).

O que aponta para a questão de medidas e quantificação, ou seja, relaciona-se estreitamente com a aritmética e geometria elementar. Mas nos 
obriga a enfrentarmos questões que colocam a quantitabilidade, ou o seu elemento puro, como um existente, com o qual o aprendiz pode entrar em contato. Este contato é o que propiciará a aprendizagem, para além de uma simples recognição de regras ou normas, como as de uma linguagem em aquisição. Constituindo-se, assim, como a primeira classe de signos de cujo encontro dependeria da Aprendizagem da Matemática.

Já a qualitabilidade é por Deleuze (1998, p. 166) referida da seguinte maneira:

Como conceito do entendimento, a quantitas tem um valor geral, a generalidade designando aqui uma infinidade de valores particulares possíveis, do mesmo modo que a variável pode recebê-los. Mas é preciso sempre um valor particular, encarregado de representar os outros e de valer por eles: é o caso da equação algébrica do círculo $x^{2}+y^{2}-R^{2}=0$.

Tal como para a quantitabilidade, também aqui com a qualitabilidade é preciso que se descubram dispositivos favoráveis à apresentação desta classe de signos, em condições de favorecer o encontro com pontos notáveis do aprendiz, como vimos nos referindo anteriormente.

Por sua vez, em relação à potencialidade, Deleuze (1998, p. 169) afirma:

Ao elemento da potencialidade corresponde um princípio de determinação completa. Não se deve confundir a determinação completa com a determinação recíproca. Esta concernia às relações diferenciais e seus graus, suas variedades na Ideia correspondendo a formas diversas. A determinação completa concerne aos valores de uma relação, isto é, à composição de uma forma ou à repartição dos pontos singulares que a caracterizam, por exemplo, quando a relação se torna nula, ou infinita, ou 0/0. Trata-se de uma determinação completa das partes do objeto: agora, é no objeto, na curva, que se deve encontrar elementos que apresentam a relação "linear" precedentemente definida. E é somente aí que a forma serial na potencialidade adquire todo seu sentido; torna-se mesmo necessário apresentar o que é uma relação como uma soma, pois uma série de potências com coeficientes numéricos cerca um ponto singular, e um só de cada vez.

A potencialidade constituiria então a terceira classe de signos, que, somada à qualitabilidade (da álgebra) e à quantitabilidade (da aritmética e da geometria elementar), completaria a Análise, na tentativa de Deleuze (1998) de fundamentá-la ontologicamente.

Esta compreensão do processo ontológico, tomando a Matemática como uma ciência empírica, nos parece imprescindível num curso de gradua- 
ção na área de ciências exatas, pois fornece os fundamentos e os conhecimentos matemáticos necessários e contingentes ao pensar as Matemáticas (nas suas mais diversas nuances: Álgebra, Geometria, Análise etc.). Otero-Garcia (2011) relata que a estrutura educacional (especificamente no ensino superior) não leva em consideração um relacionamento dos estudantes com os signos, apenas expõe conteúdos como algo a ser alcançado de forma altamente mecânica e tecnicista.

Conforme Gallo (2010), durante o século XX as teorias vigentes no campo da Educação (pedagógicas) se estabeleceram, de forma geral, centradas no vínculo: só aprendemos aquilo que nos é ensinado; não podemos aprender sem que alguém nos ensine. A partir daí, o processo educacional passa a ser tomado dentro da perspectiva da ciência, conferindo segurança e autoridade ao professor sobre como ensinar e como avaliar o aprendizado de cada aluno (Gallo, 2010). O fato de pensar o aprendizado como consequência do ensino resulta num processo de homogeneização, no qual o objetivo é fazer que todos aprendam as mesmas coisas, da mesma maneira, na mesma quantidade e no mesmo local.

Neste trabalho, daremos ênfase ao sentido ontológico de signo, que são os pontos singulares da ideia objetiva, o signo como parte da matéria. Por exemplo, repetindo uma citação de Deleuze (2003, p. 4), “alguém só se torna marceneiro tornando-se sensível aos signos da madeira". Nesse sentido, o nó de uma madeira é um problema com o qual o profissional de marcenaria precisa saber trabalhar. Afinal, aprender é descobrir em uma matéria seus pontos singulares e as relações que se estabelecem.

Se focarmos, neste momento, o encontro dos estudantes com os signos da Matemática, percebemos que, baseados nessa teoria, as turmas de Matemática incorrem num ato que pode prejudicar quaisquer encontros ou relacionamentos dos estudantes com os signos que permearão sua vida, pelo menos no sentido profissional, porque, na atual perspectiva dessa disciplina, isso acontece num processo mecânico, temporal e abstrato, podendo prejudicar o aprendizado daqueles. A questão que, então, passa a nos afligir é: como criarmos condições favoráveis para que os estudantes se tornem sensíveis aos signos da Matemática? Ou, em outras palavras: como poderíamos produzir, no que concerne aos estudantes, corpos mais sensíveis aos signos da Matemática?

Para Deleuze (1998), a disponibilidade para lidar com signos é um requisito indispensável para a Aprendizagem. Caberia, pois, àqueles que pretenderem favorecer processos de aprendizagem, descobrir dispositivos que propiciem aos aprendizes corpos mais sensíveis aos signos da Matemá- 
tica. O lugar que hoje se concebe para o professor poderia ser ocupado por um "intercessor" que lhes apresentasse a matéria a partir da qual os signos podem afetá-los, mas isto não quer dizer que ele poderia manipular os signos, o que seria contraditório com a concepção deleuzeana. Pelo contrário, propriamente falando, não é o intercessor que dispara os signos, já que os signos estão contidos na matéria, eles a constituem, mas, este intercessor deveria possuir um conhecimento dela (a matéria) que lhe permitisse uma apresentação da matéria que favorecesse o encontro dos aprendizes com os signos contidos nela.

Há ainda que considerarmos o acontecimento (inconsciente) que ocorre em nós ao relacionarmos com signos, as conexões destes com os pontos notáveis do nosso corpo (ou da nossa mente), o que pode servir para analisarmos as nuances de uma classe de Análise Matemática. Qualquer relação que venhamos a ter com pessoas ou com coisas pode despertar em nós um aprendizado, ainda que ele seja involuntário, isto é, que não tenhamos consciência disso durante o processo. E, quando percebemos que signos passam a se conectar com partes de nosso pensamento (mente ou corpo), que conseguimos concretizar algum pensamento a respeito, é que entendemos que aconteceu o aprender; quando somos capazes de perceber o que aprendemos durante aquele tempo, que nos parecia, de algum modo, perdido.

\section{Primeiros Contatos}

No processo educativo vigente em nossas universidades, os docentes esperam que, ao adentrar uma classe de Análise, o aluno possa produzir, quase que espontaneamente, um conhecimento considerado difícil tanto para alunos, como para docentes (OTERO-GARCIA, 2011), sem levar em consideração as variáveis envolvidas nesse processo. A existência de uma experiência anterior na qual o estudante tenha conseguido acessar a sensibilidade aos signos da unidade de conteúdo é fundamental para potencializar a aprendizagem. As condições por meio das quais o ambiente de aprendizagem disponibilizado em suas experiências anteriores propiciou o encontro com os signos desta área fazem toda a diferença na aquisição dos novos signos que lhes serão apresentados na universidade.

Deve-se levar em consideração que nossos primeiros contatos com os signos não se dão nos referidos semestres letivos ou no final de um curso de graduação. Eles, segundo Nascimento (2000), iniciam-se nos primeiros 
anos do ensino fundamental, ou até mesmo inconscientemente, por outros fatores, antes desse período. Desta forma, os docentes atuais parecem pressupor uma aprendizagem que, de fato, não se efetivou, seja no ensino fundamental ou no ensino médio.

Se a situação fosse de forma a favorecer a aprendizagem como encontro com os signos, poderíamos ter uma excelente relação dos estudantes com os primeiros signos matemáticos, que estruturam a Análise, quando dos conceitos de derivada e integral, que poderiam ser inicializados no estudo de funções, área de figuras e gráficos. Razões fundamentais e intervalos abertos e fechados também poderiam ser apresentados com um nível de ensino com um enfoque mais completo, sempre buscando levar os estudantes ao encontro desses temas como signos reais, num "encontro" dos mesmos com pontos notáveis de seu pensamento (problemas, questões em aberto, dúvidas centrais), estimulando a aprendizagem de fato. Tratar-se-á sempre de tornar o tema um signo para o aprendiz, nunca apenas apresentar uma definição, um conceito, a ser memorizado e posteriormente reconhecido. Nunca um estímulo à recognição, mas sim à aprendizagem no seu sentido inventivo, criativo e construtivista.

Utilizando as concepções propostas por Deleuze (1998) para refletirmos sobre a Educação Básica brasileira, pode-se considerar que, nos Ensinos Fundamental I e Fundamental II, quando os alunos não vivenciam uma experiência satisfatória de Aprendizagem, propiciada por um relacionamento sensível com seus signos, resta-lhes apenas decorar e repetir o que o professor faz e pensa, estimulando uma recognição abstrata, de algo que não se sabe o que é e nem para o que serve, e, se isso não é corrigido no ensino médio, iniciam-se muitas das mazelas apresentadas na questão da aprendizagem de conceitos puramente matemáticos no ensino superior, e principalmente na Análise.

Na perspectiva deleuziana, não podemos medir, aferir ou quantificar o quanto uma pessoa aprende, o que lhe serve de referencial. Certo é que não aprendemos copiando ou imitando, mas sim fazendo com alguém que possa nos direcionar para pensar com a diferença, sem razão de semelhança com o objeto a ser estudado.

Nunca se sabe como uma pessoa aprende; mas, de qualquer forma que aprenda, é sempre por intermédio de signos, perdendo tempo, e não pela assimilação de conteúdos objetivos. Quem sabe como um estudante pode tornar-se repentinamente "bom em latim", que signos (amorosos ou até mesmo inconfessáveis) Ihe serviriam de aprendizado? Nunca aprendemos alguma coisa nos dicionários que 
nossos professores e nossos pais nos emprestam. O signo implica em si a heterogeneidade como relação. Nunca se aprende fazendo como alguém, mas fazendo com alguém, que não tem relação de semelhança com o que se aprende (DELEUZE, 2003, p. 21).

De acordo com Gallo (2010, p. 4), "pensamos quando nos encontramos com um problema, com algo que nos força a pensar. E aprendemos quando pensamos. $O$ aprender é, pois, um acontecimento da ordem do problemático". É essa perspectiva de problema que faz com que Deleuze defenda a noção de um aprender que não é imanente à recognição, mas criação de algo novo, um acontecimento singular no pensamento, como queríamos refletir.

A noção do aprender como um acontecimento imprevisível desmonta qualquer aspiração da pedagogia moderna em tornar-se de tal maneira uma ciência, a perspectiva de planejar, controlar e medir os processos de aprendizagem. No entanto, o próprio Deleuze (1998) nos leva a pensar que, em princípio, nem o próprio aprendiz sabe que está aprendendo. Nas palavras deste autor: "não há métodos para encontrar tesouros nem para aprender" (DELEUZE, 1998, p. 237), não há como planejar o aprendizado. Mas o aprender acontece singularmente, algo que se dá em multiplicidade. Ao contrário, no âmbito da recognição, o ato de aprender nos confere algo que já possuíamos ou com que tivemos algum contato anterior; aprendemos, então, para recuperar esse algo, que já habitava nosso pensamento, mas não tínhamos conhecimento disso, que denotaremos por algum conhecimento ou algo dado.

Assim, a Análise Matemática fica condicionada à experimentação de algo novo, de algo a mais, um novo conceito, um novo conhecimento sobre algo já introduzido a priori. De acordo com Gallina (2007), experiência é o conjunto daquilo que aparece e, enquanto tal, puro movimento, puro devir. Mas no sentido que atribuímos à experimentação, por contraste à experiência, podemos dizer que ela é um acontecimento a partir do qual se infere a existência de outra coisa que ainda não está dada, daquilo que se apresenta como dado aos sentidos, que nos torna sensíveis.

\section{CONSIDERAÇÕES FINAIS}

Deleuze é radical ao transcrever a questão, ao colocar ênfase não no saber, mas no próprio aprender. Ao afirmar que "aprender é tão-somente o intermediário entre não-saber e saber, a passagem viva de um ao outro" (DELEUZE, 1998, p. 238). 
Ele enfatiza o aprender como processo, como passagem, como acontecimento, acontecimento no pensamento. Essa perspectiva é esclarecedora em relação ao aprendizado da Análise e, portanto, em toda Matemática, na qual o estudante deve colocar seu desejo no processo de aprender e vivenciar o acontecimento, relacionar-se efetivamente com os signos através dessa disciplina e todo o trajeto trilhado nesta passagem.

Em Diferença e Repetição, Deleuze (1998, p. 48) afirma que "nada aprendemos com aquele que nos diz: faça como eu. Nossos únicos mestres são aqueles que nos dizem 'faça comigo' e que, em vez de nos propor gestos a serem reproduzidos, sabem emitir signos a serem desenvolvidos no heterogêneo". Ainda neste texto, encontramos um exemplo bastante esclarecedor: o que significa aprender a nadar? Um sujeito somente aprende a nadar quando seu corpo entra em sintonia com os signos da água. Nenhum efeito teria se um sujeito resolvesse apenas "fazer como" um instrutor, um professor de natação; é perfeitamente possível saber representar e reproduzir todos os gestos de um nadador e não saber nadar.

A mesma coisa ocorre com um estudante de Matemática, que somente aprenderá Análise Matemática quando seu corpo (mente ou pensamento) estiver/entrar em contato com os signos da quantitabilidade, da qualitabilidade e da potencialidade constituintes de um processo de construção e aprendizagem que leva à Análise Matemática, que, porventura, é a base da Matemática superior. Em outras palavras, o estudante só aprenderá quando estas (quantitabilidade, qualitabilidade e potencialidade) se tornarem para ele um signo a ser decifrado, quando seus professores se ocuparem com a apresentação da matéria de modo a favorecer a atualização destes signos. Nenhum proveito teria um estudante que somente repetisse mecanicamente ou reproduzisse os resultados apresentados pelo professor, ou apenas conquistasse a posse de regras para solução dos problemas, resultado de atividades exclusivas de recognição ou reconhecimento.

Segundo Gallo (2012, p. 6), "sendo o aprender um acontecimento, ele demanda presença, demanda que o aprendiz nele se coloque por inteiro. $\mathrm{E}$ exige relação com o outro. Entrar em contato, em sintonia com os signos é relacionar-se, deixar-se afetar por eles, na mesma medida em que os afeta e produz outras afecções". O que não pode ser alcançado se não nos dispusermos a nos relacionar efetivamente com os signos que nos afetam. E falamos aqui da relação com a Matemática, que nos provoca e nos requer um tempo para entrar em contato, produzir afetos, e também buscar uma sintonia para pensarmos em Análise como signos a serem decifrados, e não somente 
na Análise Matemática enquanto uma componente curricular e conteúdos recognitivos a serem transmitidos.

O aprender é um relacionamento por completo entre nós e os signos, por isso se fazem necessárias a convivência, a presença, a aplicação ao relacionamento com todo o corpo (mente e pensamento). Deleuze afirma que no aprender "não há ideomotricidade, mas somente sensório-motricidade" (DELEUZE, 1998, p. 48), isto é, aprender não implica em um movimento na ideia, mas sim em um movimento na sensibilidade, no corpo, para nos tornar sensíveis (através da experiência sensível) para com os signos. O signo implica em si a heterogeneidade como relação:

A aprendizagem não se faz na relação da representação com a ação (como reprodução do Mesmo), mas na relação do signo com a resposta (como encontro com o Outro). O signo compreende a heterogeneidade, pelo menos de três maneiras: em primeiro lugar, no objeto que o emite ou que é seu portador e que apresenta necessariamente uma diferença de nível, como duas disparatadas ordens de grandeza ou de realidade entre as quais o signo fulgura; por outro lado, em si mesmo, porque o signo envolve um outro "objeto" nos limites do objeto portador e encarna uma potência da natureza ou do espírito (Ideia); finalmente, na resposta que ele solicita, não havendo "semelhança" entre o movimento da resposta e o do signo (DELEUZE, 1998, p. 48).

Pois percebemos que, em classes de Análise Matemática (ou de outra disciplina), há alunos que estudam de maneira distinta; uns preferem isolar-se, outros se reunir em grupos; mas certo é que cada um tem seu tempo e requer relações diferenciadas com os signos desta disciplina. A heterogeneidade abordada por Deleuze está baseada na multiplicidade; é por estar aportada nesta relação que o signo implica em heterogeneidade e em diferença, ao contrário do que prega a pedagogia escolar. E essa diferença, quando bem explorada e discutida na sala de aula, vem a potencializar uma repetição da diferença, que proporcionará modos de se aprender.

Independentemente de nossas vontades, o aprender se coloca para além daquilo que fazemos em nossas salas de aula, sempre impondo sua heterogeneidade e a criação de diferenças. A questão que nos surge vem a ser se somos capazes de reconhecer e valorizar essas diferenças, ou se permanecemos, como professores, no papel de tentar trazer todos para o mesmo lugar, na busca por uma generalização do aprendizado, o que prejudica as experiências e relações dos alunos com os signos, com os quais nos propomos trabalhar. 
Na perspectiva teórica de Gilles Deleuze, o ato de ensinar consiste em emitir signos, sem que tenhamos controle em relação ao que será feito com eles, por aqueles que com eles se encontrarem; e para isso temos que abdicar de nossa vontade de controlar o aprendizado de cada um de nossos alunos, a despeito de nossas "boas" intenções nesse processo. Lembrando, novamente, que a emissão dos signos se dá por uma apresentação da matéria, na qual os signos se destacam, independentemente de qualquer ação de quem ensina. Cabe apenas apresentar a matéria da forma mais competente que for possível, assim os signos se destacarão.

Precisamos ousar ensinar, ousar pensar numa concepção de ensino diferente,

[...] como quem lança sementes ao vento, com a esperança dos encontros que possam produzir, das diferenças que possam fazer vingar, nos encantando com as múltiplas criações que podem ser produzidas a partir delas, não desejando que todos façam da mesma maneira, sejam da mesma maneira. [...] O desapego que precisamos exercitar como professores é a preparação para nosso desaparecimento; se somos capazes de, ao emitir signos, mobilizar nos alunos o acontecimento aprender, então já não somos necessários depois disso. Abrimos o caminho; que caminho será esse, cada aluno escolherá, inventará e trilhará, em sua singularidade. (GALLO, 2012, p. 10).

Uma unidade de conteúdo acadêmico tão criticada e estudada por suas peculiaridades, como a Análise Matemática, carece de renovação na forma como vem sendo trabalhada. Neste artigo, sugerimos que esta mudança se dê na direção da heterogeneidade e multiplicidade, da invenção de novos ambientes, nos quais o aprendizado, como decifração de signos, possa ser favorecido em nossos aprendizes. O que implica num desapego da importância dada ao ato tradicional de ensinar manifesto em metodologias cristalizadas, para que passemos a considerar a tarefa de emissão de signos de forma heterogênea e múltipla, de modo a favorecer a singularidade dos alunos, como fundamental condição de possibilidade da produção da aprendizagem efetiva. 
TEACHING AND LEARNING MATHEMATICAL ANALYSIS AS ENCOUNTER WITH SIGNS FROM THE PERSPECTIVE OF GILLES DELEUZE

ABSTRACT: This article reflects on the discipline of Mathematical Analysis in courses of exact sciences from a philosophical point of view. The main objective is to look at some critical issues of the teaching and learning in this discipline. In order to investigate this object of study as a sign and an event in thought, we seek to review the problems of this subject based on Gilles Deleuze's theory and its conceptual shift to the field of Mathematical Education. This philosopher proposes us to think of learning as a process, as passing, as an event, an event in thought. From this perspective the learning of Mathematical Analysis can be conceived as the development of sensitivity in apprentices to the signs of this discipline and it becomes the condition for its effectuation.

KEYwords: Mathematical Analysis. Signs. Teaching and Learning. Gilles Deleuze.

\section{LA ENSEÑANZA Y EL APRENDIZAJE DE ANÁLISIS MATEMÁTICA COMO ENCUENTRO CON LOS SIGNOS DESDE LA PERSPECTIVA DE GILLES DELEUZE}

RESUMEN: En este artículo se presentan reflexiones acerca de la asignatura Análisis Matemática en los cursos de ciencias exactas desde un punto de vista filosófico. El objetivo principal es atender cuestiones críticas de la enseñanza y del aprendizaje de esta asignatura. Para investigar este objeto de estudio como signo y acontecimiento en el pensamiento, buscamos un análisis sobre la problemática de esta asigantura basados en la teoría de Gilles Deleuze y su movimiento conceptual en el campo de la Educación Matemática. Ese filósofo propone pensar el aprender como un proceso, como camino, como acontecimiento en el pensamiento. Desde esa perspectiva el aprendizaje del análisis matemático pasa a ser concebido como el desarrollo de una sensibilidad de aprendices a los signos de esta asignatura, y se convierte e una condición para su concretización.

Palabras-clave: Análisis Matemática. Signos. Enseñanza y Aprendizaje. Gilles Deleuze.

\section{REFERÊNCIAS}

CORRÊA, R. de A. Linguagem Matemática, meios de comunicação e Educação Matemática. In: NACARATO, A.; LOPES, C. E. (Org.). Escritas e leituras na Educação Matemática. Belo Horizonte: Autêntica, 2005. p. 93-100.

CURY, H. N. Aprendizagem em Cálculo: uma experiência com avaliação formativa. In: XXVIII Congresso Nacional de Matemática Aplicada e Computacional. Santo Amaro, 2005. 
DELEUZE, G. Diferença e repetição. Rio de Janeiro: Graal, 1998.

. Proust e os Signos. Tradução Antônio Carlos Piquet e Roberto Machado.

Cidade: Ed. Forense, 2003.

DELEUZE, G; GUATTARI, F. Mil Platôs - Capitalismo e esquizofrenia. Vol. 2. Tradução de Ana Lúcia de Oliveira e Lúcia Cláudia Leão. São Paulo: Ed. 34, 1995.

GALLINA, S. F. S. Deleuze e Hume: Experimentação e Pensar. Philósophos, Rio Grande do Sul, v. 12, n.1, jan-jun. 2007.

GALLO, S. Filosofias da diferença e Educação. In: CLARETO, S. M.; FERRARI, A. (Org.). Foucault, Deleuze \& Educação. Juiz de Fora: Editora UFJF, 2010. p. 49-63.

. As Múltiplas Dimensões do Aprender. In: Congresso de Educação Básica: Aprendizagem e Currículo - COEB - Florianópolis/SC. 2012.

NASCIMENTO, J. L. Uma Proposta Metodológica Para a Disciplina de Cálculo I. In: VI Encontro de Educação em Engenharia. Escola Politécnica da UFRJ. Rio de Janeiro, 2000.

NASSER, L.; FREIRE, J. L.; CARDADOR, D. Preenchendo Lacunas de Aprendizagem em Educação Matemática no Ensino Superior por meio da Educação a Distância. In: VI SPEM - Seminário de Pesquisa em Educação Matemática do Estado do Rio de Janeiro. UNIRIO, 2008.

OTERO-GARCIA, S. C. Uma Trajetória da Disciplina de Análise e um Estado do Conhecimento sobre seu Ensino. Dissertação Mestrado em Educação Matemática - Universidade Estadual Paulista - UNESP, Rio Claro, SP. 2011.

; CAMMAROTA, G. Aprendizagem e Formação do Professor de Matemática sob os Vieses da Disciplina de Análise e da Noção de Cognição Inventiva. In: LEITE, Y. U. F.; MARIN, A. J.; PIMENTA, S. G.; GOMES, M. O.; REALI, A. M. M. R. (Org.). Políticas de Formação Inicial e Continuada de Professores. Araraquara: Junqueira \& Marin Editores, 2012. p. 6482-6493.

PASCUAL, E. S. Matemáticas y Estilos de Aprendizaje. Revista Estilos de Aprendizaje, v. 4, n. 4, out. 2009.

PETRONILIO, P. Literatura, Vida e Linguagem em Gilles Deleuze. Rev. Guará, Goiânia, V. 2, n. 1, p. 50-69, jan./jun. 2012.

PICKOVER, C. A. The Mathematics Devotional: Celebrating the Wisdom and Beauty of Mathematics. Ed Sterling, 2014. 392 p.

ROQUE, T. História da Matemática. Cidade: Ed. Zahar, 2012.

SILVA, B. A. Diferentes dimensões do ensino e aprendizagem do Cálculo. Educ. Matem. Pesq., São Paulo, v. 13, n. 3, p. 393-413, 2011.

SILVA, C. P. Aspectos históricos do desenvolvimento da pesquisa Matemática no Brasil: História da Matemática para professores. São Paulo: Ed. Livraria da Física, 2009. 
SOTOMAYOR, J. Fourier e a Análise Matemática: Tradução livre, por Jorge Sotomayor, de fragmento da Introdução de "A Teoria do Calor" por J. L. Fourier, 1768-1830. 2004. Disponível em: <http://www.ime.usp.br/ rfreire/calculo/four.pdf>. Acesso em: 23 jan. 2016.

Luiz Carlos Leal Junior: Doutorando em Educação Matemática pela Universidade Estadual Paulista (Unesp). Atualmente é professor efetivo do Instituto Federal de Educação, Ciência e Tecnologia de São Paulo. Tem experiência na área de Educação, com ênfase em Educação Matemática e Análise, atuando principalmente nos seguintes temas: educação matemática, filosofia e teoria da aproximação.

E-mail: jhcleal@gmail.com

Antonio dos Santos Andrade: Doutor em Psicologia Escolar e do Desenvolvimento Humano pelo Instituto de Psicologia da Universidade de São Paulo (USP). Atualmente é professor doutor da Faculdade de Filosofia, Ciências e Letras de Ribeirão Preto, da Universidade de São Paulo, responsável pela disciplina de Psicologia Escolar na graduação em Psicologia. Tem experiência na área de Psicologia, com ênfase em Psicologia Escolar, atuando principalmente nos seguintes temas: produção de subjetividade em educação, etnografia educacional, sociodrama educacional e análise de instituições educacionais.

E-mail: antandras@ffclrp.usp.br 